\title{
Spectacular inflammatory linear verrucous epidermal nevus (ILVEN)
}

\section{Mohamed El Amraoui, Rachid Frikh, Naoufal Hjira, Mohammed Boui}

\author{
Department of Dermatology-Venereology, Mohammed V Military Training Hospital, Rabat, Morocco
}

Corresponding author: Dr. Mohamed El Amraoui, E-mail: med.elamraoui.dto@gmail.com

A 16-year-old man, with no similar cases in the family, consulted for brown wart lesions that appeared at the age of two years with an extensive tendency for 4 years (Fig. la and $1 b$ ). Clinical and histological examination was in favor of an inflammatory linear verrucous epidermal nevus (ILVEN). Retinoids were tested without any improvement and laser was indicated but the patient was lost to follow-up. ILVEN is a rare condition corresponding to benign epidermal hyperplasia, which present clinically in the form of unilateral hyperkeratotic linear lesions resulting from a phenomenon of genomic mosaicism. Evolution is chronic with exudative and pruritic flare-ups. A secondary extension of the lesions is also possible as in our patient. Various anomalies may be associated such as aplasia of a limb part. Distinction with linear psoriasis can be difficult histologically. Retinoids and local corticosteroids are not very effective, surgical excision is sometimes practiced and $\mathrm{CO} 2$ laser finds its place in this indication with satisfactory results [1-3].

\section{Consent}

The examination of the patient was conducted according to the Declaration of Helsinki principles.

The authors certify that they have obtained all appropriate patient consent forms. In the form the patient(s) has/have given his/her/their consent for his/her/their images and other clinical information to be reported in the journal. The patients understand that their names and initials will not be published and due efforts will be made to conceal their identity, but anonymity cannot be guaranteed.

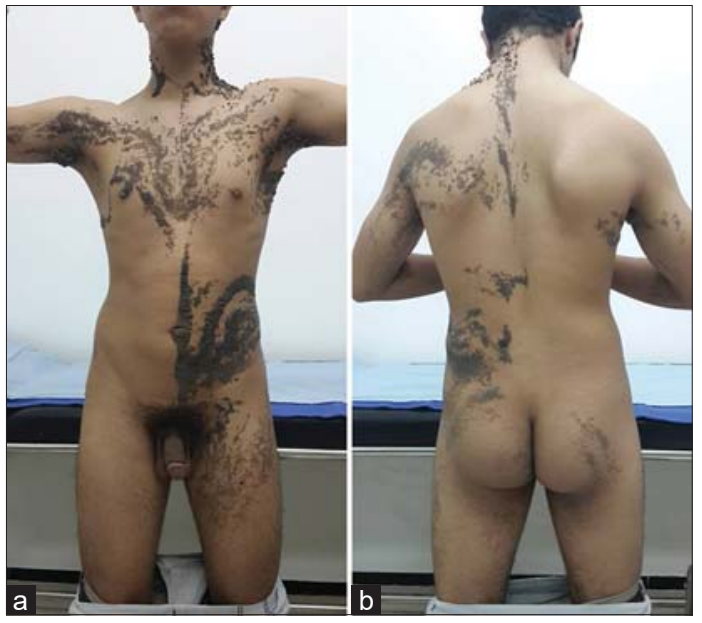

Figure 1: $(a$ and $b)$ Hyperpigmented wart lesions with a blashko-linear disposition, bilateral with predominance at the left side of body.

\section{REFERENCES}

1. Yorulmaz A, Cakmak S, Hazar Tantoglu B, Artuz F, Kadan E, Sen E. Inflammatory linear verrucous epidermal nevus syndrome. Our Dermatol Online. 2015;6:369-71.

2. Gianfaldoni S, Tchernev G, Gianfaldoni R, Wollina U, Lotti T. A Case of "Inflammatory Linear Verrucous Epidermal Nevus" (NEVIL) treated with CO2 laser ablation. Open Access Maced J Med Sci. 2017;5:454-7.

3. Tanita K. Fujimura T. Sato Y, Lyu C, Aiba S. Widely spread unilateral Inflammatory Linear Verrucous Epidermal Nevus (ILVEN). Case Rep Dermatol. 2018;10:170-5.

Copyright by Mohamed El Amraoui, et al. This is an open-access article distributed under the terms of the Creative Commons Attribution License, which permits unrestricted use, distribution, and reproduction in any medium, provided the original author and source are credited.

Source of Support: Nil, Conflict of Interest: None declared. 